\title{
O PROCESSO DE TRANSFORMAÇÃO DA UNIVERSIDADE BRASILEIRA E OS PROFESSORES UNIVERSITÁRIOS À LUZ DA LEI N 5540/68: PASSADO OU PRESENTE?
}

\author{
Alexandre Shigunov Neto \\ Ivan Fortunato \\ Instituto Federal de Educaçao, Ciència e Tecnologia de São Paulo, campus \\ Itapetininga, Brasil
}

\section{RESUMO}

O presente artigo pretende realizar algumas reflexões iniciais sobre o processo de transformação da universidade brasileira e a questão da formação de professores universitários à luz da Lei $n^{\circ} 5.540 / 68$.

\section{PALAVRAS-CHAVE}

Educação - educação superior - universidade - professores

\begin{abstract}
This article intends to carry out some initial reflections about the Brazilian University and University teacher education processes of transformation promoted by Federal Law $n^{\circ}$. 5540/68.
\end{abstract}

\section{KEYWORDS}

Education - higher education - university - teachers

\section{RESUMEN}

En este artículo se propone llevar a cabo algunas reflexiones iniciales sobre el proceso de transformación de la universidad brasileña y la cuestión de la formación de los docentes universitarios a la luz de la Ley $N^{\circ} 5.540 / 68$.

\section{Palabras clave}

Educación - educación superior - universidad - profesores 